\title{
The boundary layer flow of Casson nanofluid over a vertical exponentially stretching cylinder
}

\author{
M. Y. Malik • M. Naseer • \\ S. Nadeem • Abdul Rehman
}

Received: 24 July 2013/Accepted: 23 August 2013/Published online: 18 September 2013

(C) The Author(s) 2013. This article is published with open access at Springerlink.com

\begin{abstract}
In this paper, an analysis is carried out for the similarity solution of the steady boundary layer flow and heat transfer of a Casson nanofluid flowing over a vertical cylinder which is stretching exponentially along its radial direction. Using boundary layer approach and suitable similarity transformation the governing partial differential equations with the boundary conditions are reduced to a system of nonlinear ordinary differential equations. The resulting system is solved with the help of numerical technique, the Runge-Kutta Fehlberg method. The effects of important parameters such as Reynolds number, Prandtl number, Lewis number and the natural convection parameter are described through graphs.
\end{abstract}

Keywords Boundary layer flow - Vertical cylinder . Casson nanofluid - Natural convection heat transfer . Fehlberg method

\section{Introduction}

Casson nanofluid in cylindrical geometry has important application in blood flow. Mathematicians as well as medical researcher are widely working on Casson nanofluid model. Rehman and Nadeem (2012) have examined

M. Y. Malik · M. Naseer $(\bowtie) \cdot$ S. Nadeem

Department of Mathematics, Quaid-i-Azam University,

45320, Islamabad 44000, Pakistan

e-mail: naseermaths@yahoo.com

A. Rehman

Department of Mathematics, University of Balochistan, Quetta, Pakistan the mixed convection heat transfer in micropolar nanofluid over a vertical slender cylinder. In another paper, Nadeem et al. (2013a) investigated the boundary layer flow and heat transfer of a nanofluid over a vertical slender cylinder. Recently, Makinde et al. (2013) presented the analysis of buoyancy effects on MHD stagnation point flow and heat transfer of a nanofluid past a convectively heated stretching/shrinking sheet. Habibi and Pop (2013) published their work on natural convection flow and heat transfer in an eccentric annulus filled by copper nanofluid. Xu et al. (2013) worked on the analysis of mixed convection flow of a nanofluid in a vertical channel with the Buogiorno mathematical model. Rashidi et al. (2013) have discussed the entropy generation in steady MHD flow due to a rotating porous disk in a nanofluid. Some interesting studies concerning the fluid flow over cylindrical surfaces may include the works of Anwar et al. (2008), Gorla and Ameri (1985), Ishak et al. (2008), Wang (2012), Malik et al. (2009), Malik et al. (2011) and Nadeem et al. (2012b), while some interesting work regarding nanoparticle effects over different flow situations may include the efforts of Abdul Rehman et al. (2013), Nadeem et al. (2013a), Ellahi et al. (2013), Nadeem et al. (2012c), Nadeem et al. (2013b) and Nadeem et al. (2013c)

Boundary layer flow of Casson fluid over different geometries is considered by many authors in recent years. Nadeem et al. (2012a) presented MHD flow of a Casson fluid over an exponentially shrinking sheet. Kumari et al. (2011) analysed peristaltic pumping of a MHD Casson fluid in an inclined channel. Sreenadh et al. (2011) studied the flow of a Casson fluid through an inclined tube of non uniform cross-section with multiple stenoses. Mernone and Mazumdar (2002) discussed the peristaltic transport of a Casson fluid. Porwal and Badshah (2012) work on steady 
blood flow with Casson fluid along an inclined plane influenced by the gravity force.

In this paper, a boundary layer flow of a Casson nanofluid over a vertical exponentially stretching cylinder is studied. A system of non linear partial differential equations is obtained using boundary layer approximation. After applying suitable transformation, a system of non linear ordinary differential equations with boundary conditions is obtained. Runge-Kutta Fehlburg method is used to solve the system. The variation of different parameters is graphically shown.

\section{Formulation}

Consider the problem of natural convection boundary layer flow of a Casson nanofluid flowing over a vertical circular cylinder of radius $a$. The cylinder is assumed to be stretched exponentially along the radial direction with velocity $U_{w}$. The temperature at the surface of the cylinder is assumed to be $T_{w}$ and the uniform ambient temperature is taken as $T_{\infty}$ such that the quantity $T_{w}-T_{\infty}>0$ in case of the assisting flow, while $T_{w}-T_{\infty}<0$ in case of the opposing flow, respectively. Under these assumptions the boundary layer equations of motion heat transfer and nano particle concentration are

$u_{r}+\frac{u}{r}+w_{z}=0$,

$$
\begin{aligned}
u w_{r}+w w_{z}= & -\frac{1}{\rho} \frac{\partial p}{\partial z}+v\left(1+\frac{1}{\beta}\right)\left(w_{r r}+\frac{1}{r} w_{r}\right)+g \beta\left(T-T_{\infty}\right)\left(1-\phi_{\infty}\right) \\
& +\frac{1}{\rho}\left(\rho^{*}-\rho\right)\left(\phi-\phi_{\infty}\right)
\end{aligned}
$$

$u T_{r}+w T_{z}=\alpha\left(T_{r r}+\frac{1}{r} T_{r}\right)+\frac{\rho^{*} C_{p}^{*}}{\rho C_{p}}\left(D_{T} T_{r} \phi_{r}+\frac{D_{T}}{T_{\infty}} T_{r}^{2}\right)$,

$w \phi_{z}+u \phi_{r}=D_{B}\left(\phi_{r r}+\frac{1}{r} \phi_{r}\right)+\frac{D_{T}}{T_{\infty}}\left(T_{r r}+\frac{1}{r} T_{r}\right)$,

where the velocity components along the $(r, z)$ axes are $(u, w), \rho$ is the density, $v$ is the kinematic viscosity, $p$ is pressure, $g$ is the gravitational acceleration along the $z$ direction, $\beta$ is the coefficient of thermal expansion, $T$ is the temperature and $\alpha$ is the thermal diffusivity. The corresponding boundary conditions for the problem are

$u(a, z)=0, w(a, z)=U_{w} w(r, z) \rightarrow 0$ as $r \rightarrow \infty$,

$T(a, z)=T_{w}(z), \quad T(r, z) \rightarrow T_{\infty}$ as $r \rightarrow \infty$,

$\phi(a, z)=\phi_{w}(z), \phi(r, z) \rightarrow \phi_{\infty}$ as $r \rightarrow \infty$,

where $U_{w}=2 a k \mathrm{e}^{z / a}$ is the fluid velocity at the surface of the cylinder.

\section{Solution of the problem}

Introduce the following similarity transformations:

$u=-\frac{1}{2} U_{w} \frac{f(\eta)}{\sqrt{\eta}}, \quad w=U_{w} f^{\prime}(\eta)$,

$\theta=\frac{T-T_{\infty}}{T_{w}-T_{\infty}}, \quad \eta=\frac{r^{2}}{a^{2}}, \quad h=\frac{\phi-\phi_{\infty}}{\phi_{w}-\phi_{\infty}}$

where the characteristic temperature and nano concentration difference are calculated from the relations $T_{w}-T_{\infty}=c \mathrm{e}^{z / a}$ and $\varphi_{w}-\varphi_{\infty}=\mathrm{e}^{z / a}$. With the help of transformations (8) and (9), Eqs. (1)-(4) take the form

$$
\begin{aligned}
& \left(1+\frac{1}{\beta}\right)\left(\eta f^{\prime \prime \prime}+f^{\prime \prime}\right)+\operatorname{Re}\left(f f^{\prime \prime}-f^{\prime 2}\right)+\operatorname{Re} \lambda\left(1-\phi_{\infty}\right) \\
& \left(\theta+N_{\mathrm{r}} h\right)=0 \\
& \eta \theta^{\prime \prime}+\theta^{\prime}+\operatorname{Re} \operatorname{Pr}\left(f \theta^{\prime}-f^{\prime} \theta\right)+\eta \theta^{\prime}\left(N_{\mathrm{b}} h^{\prime}+N_{\mathrm{t}} \theta^{\prime}\right)=0 \\
& \eta h^{\prime \prime}+h^{\prime}+\frac{N_{\mathrm{t}}}{N_{\mathrm{b}}}\left(\eta \theta^{\prime \prime}+\theta^{\prime}\right)+\operatorname{Re} \operatorname{Le}\left(f h^{\prime}-f^{\prime} h\right)=0
\end{aligned}
$$

in which $\lambda=g \beta a\left(T_{w}-T_{\infty}\right) / U_{w}^{2}$ is the buoyancy (natural convection) parameter, $\operatorname{Pr}=v / \alpha$ is the Prandtl number, $L e=v / D_{B}$ is the Lewis number, $N_{\mathrm{r}}=\left(\rho^{*}-\rho\right)\left(\varphi_{w}-\right.$ $\left.\varphi_{\infty}\right) / \rho \beta\left(T_{w}-T_{\infty}\right)\left(1-\varphi_{\infty}\right)$ is the buoyancy ratio, $N_{\mathrm{b}}=$ $\rho^{*} C_{p}^{*} D_{B}\left(\varphi_{w}-\varphi_{\infty}\right) / \rho C_{p} \alpha$ is the Brownian motion parameter, $\quad N_{\mathrm{t}}=\rho^{*} C_{p}^{*} D_{T}\left(\varphi_{w}-\varphi_{\infty}\right) / \rho C_{p} \alpha T_{\infty} \quad$ is the thermophoresis parameter and $R e=a U_{w} / 4 v$ is the Reynolds number. The boundary conditions in nondimensional form become

$f(1)=0, f^{\prime}(1)=1, f^{\prime} \rightarrow 0$, as $\eta \rightarrow \infty$,

$\theta(1)=1, \theta \rightarrow 0$, as $\eta \rightarrow \infty$.

$h(1)=1, h \rightarrow 0$, as $\eta \rightarrow \infty$.

The important physical quantities such as the shear stress at the surface $\tau_{w}$, the skinfriction coefficient $c_{f}$, the heat flux at the surface of the cylinder $q_{w}$ and the local Nusselt number $\mathrm{Nu}$ are

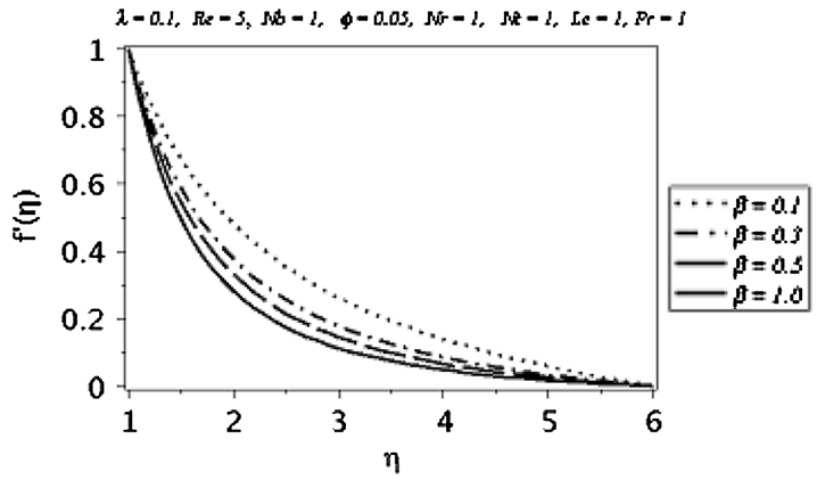

Fig. 1 The influence of Casson fluid parameter on velocity profile 


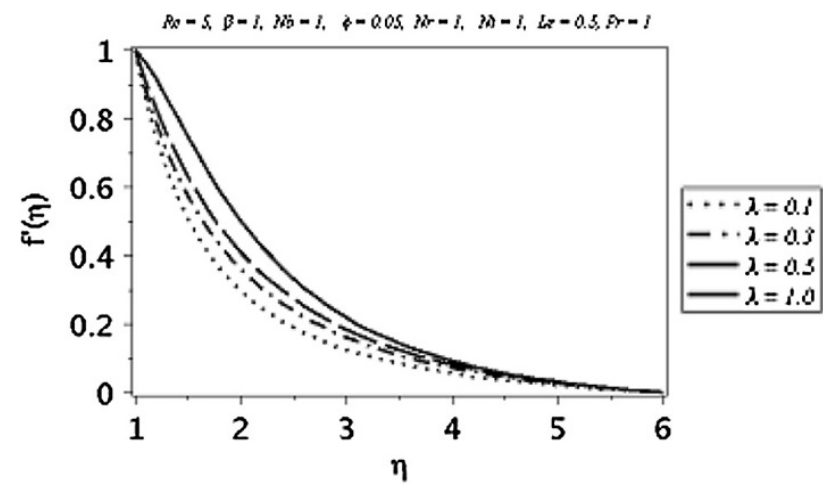

Fig. 2 The influence of natural convection parameter on velocity profile

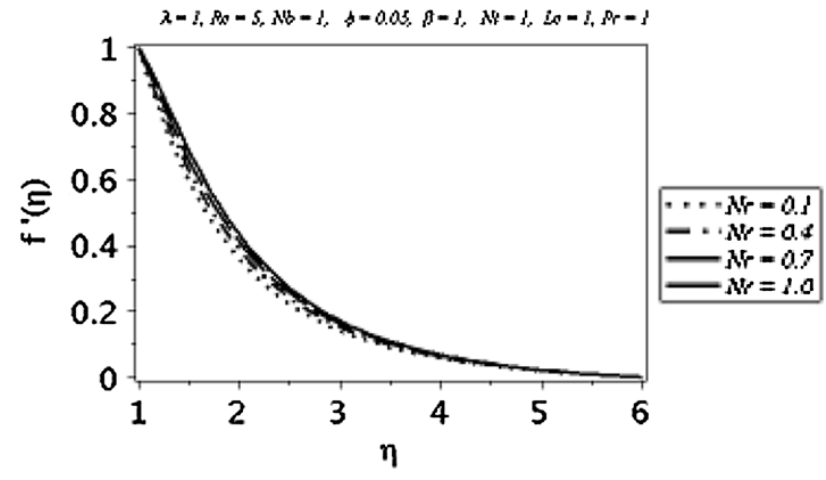

Fig. 3 The influence of buoyancy ratio parameter on velocity profile

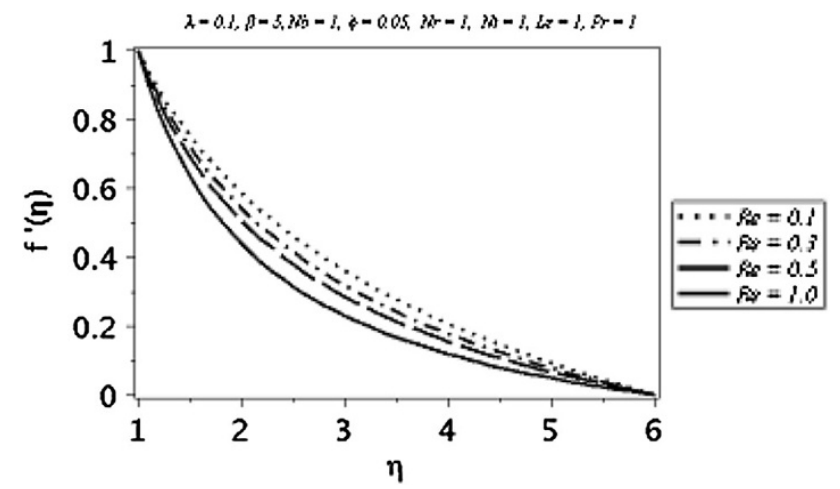

Fig. 4 The influence of Reynolds numbers on velocity profile

$$
\begin{gathered}
\tau_{w}=\left.w_{r z}\right|_{r=a}, \quad q_{w}=-\left.k T_{r}\right|_{r=a}, \\
c_{f}=\frac{\tau_{w}}{\rho U_{w}^{2}}, N u_{z}=\frac{a e^{z / a} q_{w}}{k\left(T_{w}-T_{\infty}\right)}
\end{gathered}
$$

The solution of the present problem is obtained using the numerical technique the Runge-Kutta Fehlberg method.

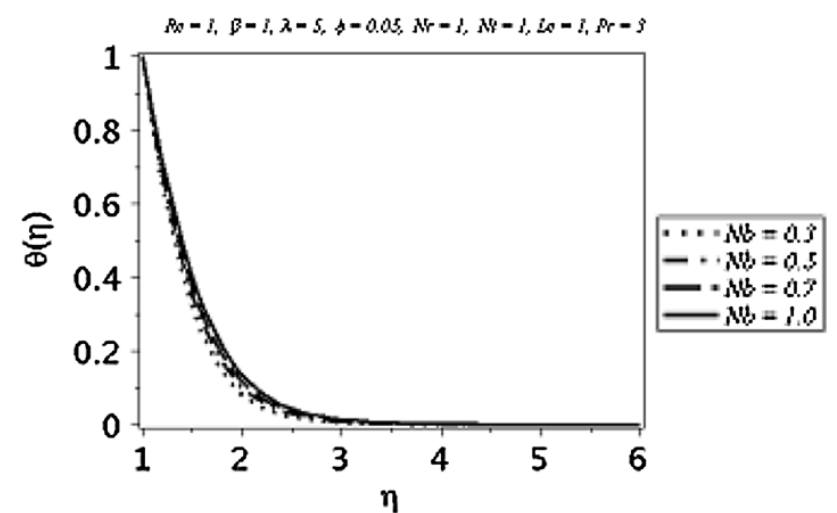

Fig. 5 The influence of Brownian motion parameter on temperature profile

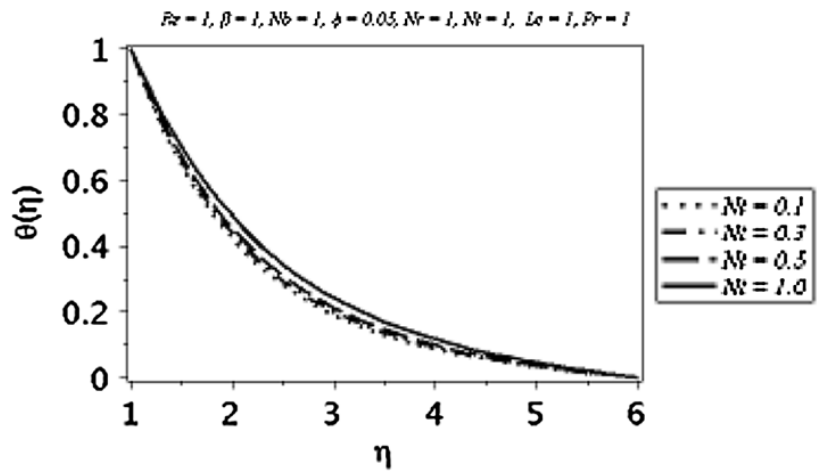

Fig. 6 The influence of thermophoresis parameter on temperature profile

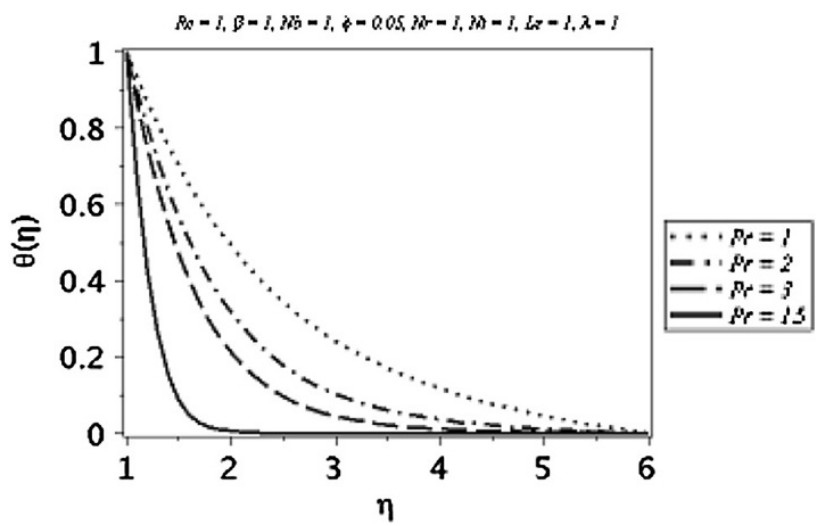

Fig. 7 The influence of Prantdle numbers on temperature profile

\section{Results and discussion}

The problem of mixed convection boundary layer flow of a Casson nanofluid over an exponentially stretched cylinder is studied in this paper. The cylinder is assumed to be stretched exponentially along its radial direction. The 
exponential stretching velocity at the surface of the cylinder is assumed to be $U_{w}=2 a k e^{z / a}$. The solution of the problem is obtained numerically with the help of RungeKutta Fehlberg method. The effect of the various parameters such as the Reynolds number $R e$, the Casson fluid parameter $\beta$, the Brownian motion parameter $N_{\mathrm{b}}$, the thermophoresis parameter $N_{\mathrm{t}}$, the buoyancy ratio parameter $N_{\mathrm{r}}$, the Prandtl number $\operatorname{Pr}$ and the mixed convection parameter $\lambda$ over the nondimensional velocity, temperature and concentration profiles are presented graphically and in the form of tables. Figure 1 shows the effect of Casson fluid parameter $\beta$ on the velocity profile $f^{\prime}$. From Fig. 1, it is observed that for increasing the value of $\beta$ the velocity profile decreases. Figure 2 shows the influence of mixed convection parameter $\lambda$ over the velocity profile $f^{\prime}$, when mixed convection parameter $\lambda$ increases the velocity profile also increases. That is the mixed convection parameter $\lambda$ is directly proportional to the velocity profile $f^{\prime}$ for constant values of other parameters. Similar pattern is seen for the buoyancy ratio $N_{\mathrm{r}}$ in Fig. 3. In Fig. 4 by increasing the value of Reynolds number $R e$ the velocity profile decreases. Figures 5 and 6 show a very slow increase in temperature profile by increasing the values of Brownian

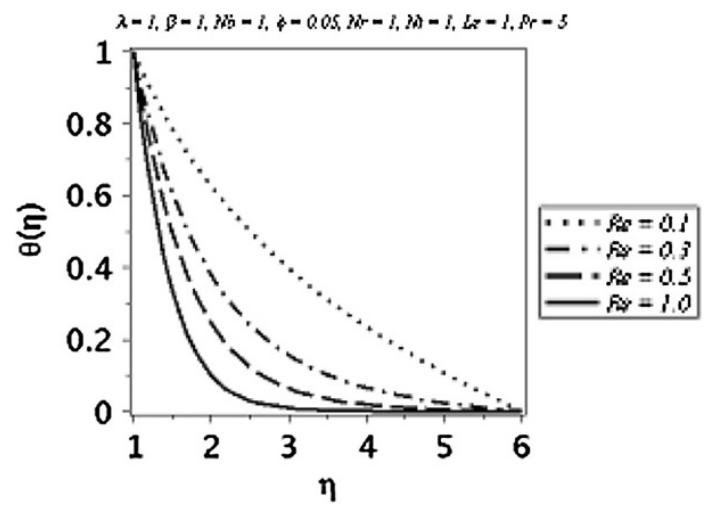

Fig. 8 The influence of Reynolds numbers on temperature profile

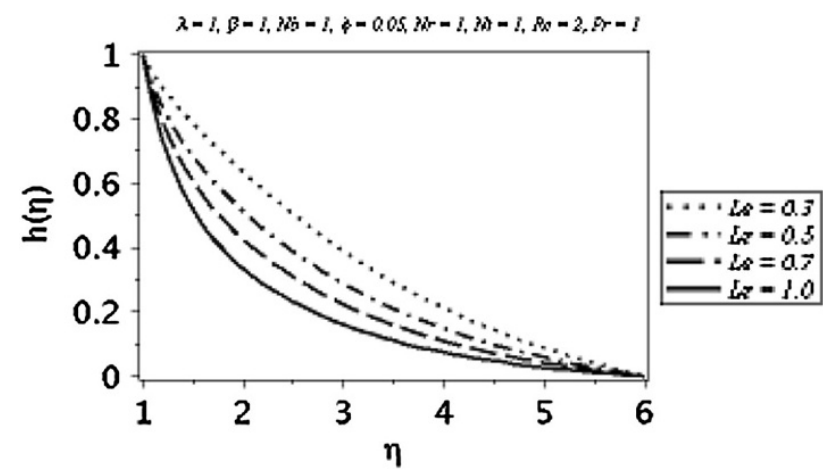

Fig. 9 The influence of Lewis numbers on concentration profile motion parameter $N_{\mathrm{b}}$ and the thermophoresis parameter $N_{\mathrm{t}}$. Figures 7 and 8 show similar behaviour of temperature profile by increasing the values of Reynolds number $R e$ and the Prantdle number $\mathrm{Pr}$, the temperature profile decreases rapidly. In Fig. 9 it is clear that by increasing the value of Lewis number $L e$ the nano concentration profile decreases instantly. In Fig. 10 a very slow upraising effect of Reynolds number $R e$ on nano concentration profile by increasing the value of Reynolds number $R e$. Table 1 shows the boundary derivatives for the velocity profile at the surface of the cylinder that corresponds to the skin friction coefficient at the surface tabulated for different values of $\beta$ and $\lambda$. From the table, it is observed that the

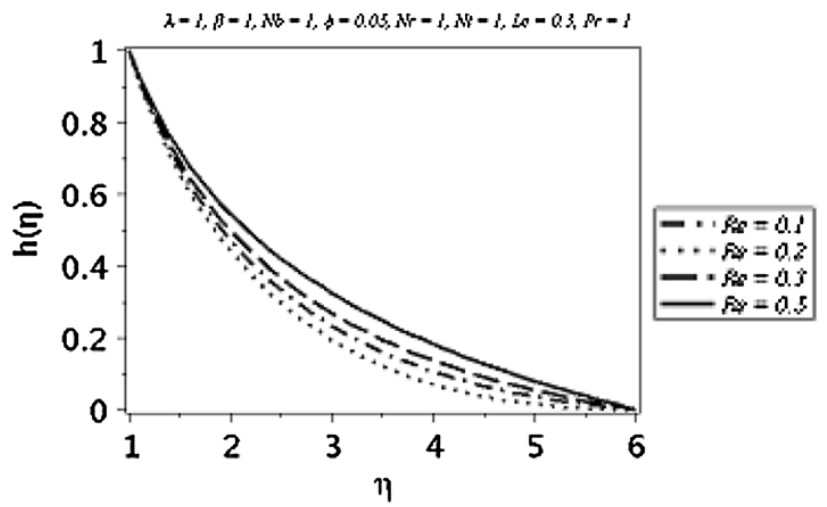

Fig. 10 The influence of Reynolds numbers on concentration profile

Table 1 Skinfriction coefficient at the surface

\begin{tabular}{llllll}
\hline$-f^{\prime \prime}(1)$ & & & & & \\
\hline$\lambda / \beta$ & 0.1 & 0.3 & 0.5 & 0.7 & 1.0 \\
\hline 0.2 & 0.8494 & 1.1283 & 1.2789 & 1.3769 & 1.4747 \\
0.4 & 0.7873 & 0.9860 & 1.0848 & 1.1459 & 1.2048 \\
0.6 & 0.7263 & 0.8490 & 0.8997 & 0.9273 & 0.9507 \\
0.8 & 0.6662 & 0.7162 & 0.7217 & 0.7177 & 0.7082 \\
1.0 & 0.6070 & 0.5869 & 0.5493 & 0.5154 & 0.4745 \\
\hline
\end{tabular}

Table 2 Local Nusselt numbers

\begin{tabular}{llllll}
\hline$-\theta^{\prime}(1)$ & & & & & \\
\hline $\operatorname{Pr} / \operatorname{Re}$ & 0.1 & 0.2 & 0.3 & 0.4 & 0.5 \\
\hline 1 & 0.2442 & 0.3094 & 0.3700 & 0.4260 & 0.4776 \\
3 & 0.3826 & 0.5627 & 0.7173 & 0.8505 & 0.9668 \\
5 & 0.5118 & 0.7844 & 1.0058 & 1.1904 & 1.3489 \\
7 & 0.6327 & 0.9814 & 1.2546 & 1.4790 & 1.6714 \\
15 & 1.0499 & 1.6121 & 2.0318 & 2.3762 & 2.6739 \\
\hline
\end{tabular}


magnitude of the boundary derivative increases with the increase in $\beta$ and decreases by increasing the values of $\lambda$. Table 2 shows the values for local Nusselt numbers calculated for different values of $R e$ and $P r$. From entries in the Table 2 it is noticed that with increase in $R e$ and $P r$, local Nusselt number increases.

Open Access This article is distributed under the terms of the Creative Commons Attribution License which permits any use, distribution, and reproduction in any medium, provided the original author(s) and the source are credited.

\section{References}

Anwar I, Amin N, Pop I (2008) Mixed convection boundary layer flow of a viscoelastic fluid over a horizontal circular cylinder. Int J Non Linear Mech 43:814-821

Ellahi R, Riaz A, Nadeem S (2013) A theoretical study of Prandtl nanofluid in a rectangular duct through peristaltic transport. Appl Nanosci. doi:10.1007/s13204-013-0255-4

Gorla RGR, Ameri A (1985) Boundary layer flow of a micropolar fluid on a continuous moving cylinder. Acta Mech 57:203-214

Habibi Matin M, Pop I (2013) Natural convection flow and heat transfer in an eccentric annulus filled by Copper nanofluid. Int $\mathrm{J}$ Heat Mass Transf 61:353-364

Ishak A, Nazar R, Pop I (2008) Uniform suction/blowing effect on flow and heat transfer due to a stretching cylinder. App Math Mod 32:2059-2066

Kumari SVHNK, Murthy MVR, Reddy MCK, Kumar YVKR (2011) Peristaltic pumping of a magnetohydrodynamic Casson fluid in an inclined channel. Adv Appl Sci Res 2(2):428-436

Makinde OD, Khan WA, Khan ZH (2013) Buoyancy effects on MHD stagnation point flow and heat transfer of a nanofluid past a convectively heated stretching/shrinking sheet. Int J Heat Mass Transf 62:526-533

Malik MY, Hussain A, Nadeem, Hayat T (2009) Flow of a third grade fluid between coaxial cylinders with variable viscosity. Zeitschrift fur Naturforschung 64a:588-596

Malik MY, Hussain A, Nadeem S (2011) Flow of a Jeffery-six constant fluid between coaxial cylinders with heat transfer analysis. Commun theor phys 56:345-351
Mernone AV, Mazumdar JN (2002) A mathematical study of peristaltic transport of a Casson fluid. Math Comp Mod 35:895-912

Nadeem S, Haq RU, Lee C (2012a) MHD flow of a Casson fluid over an exponentially shrinking sheet. Scientia Iranica 19:1550-1553

Nadeem S, Rehman A, Lee C, Lee J (2012b) Boundary layer flow of second grade fluid in a cylinder with heat transfer. Math Prob Eng. doi:10.1155/2012/640289

Nadeem S, Rehman A, Vajravelu K, Lee J, Lee C (2012c) Axisymmetric stagnation flow of a micropolar nanofluid in a moving cylinder. Math Prob Eng. doi:10.1155/2012/378259

Nadeem S, Rehman A, Ali ME (2013) The boundary layer flow and heat transfer of a nanofluid over a vertical slender cylinder. J Nanoeng Nanosyst. doi:10.1177/1740349912453806

Nadeem S, Rehman A (2013b) Axisymmetric stagnation flow of a nanofluid in a moving cylinder. Comp Math Mod 24(2):293-306

Nadeem S, Riaz A, Ellahi R, Akbar NS (2013c) Mathematical model for the peristaltic flow of Jeffrey fluid with nanoparticles phenomenon through a rectangular duct. Appl Nanosci. doi:10. 1007/s13204-013-0238-5

Porwal P, Badshah VH (2012) Analysis of steady blood flow with casson fluid along an inclined plane influenced by the gravity force. Int J Theor Appl Sci 4(2):76-81

Rashidi MM, Abelman S, Freidooni Mehr N (2013) Entropy generation in steady MHD flow due to a rotating porous disk in a nanofluid. Int $\mathrm{J}$ Heat Mass Transf 62:515-525

Rehman A, Nadeem S (2012) Mixed convection heat transfer in micropolar nanofluid over a vertical slender cylinder. Chin Phys Lett 29(12):124701

Rehman R, Nadeem S, Malik MY (2013) Stagnation flow of couple stress nanofluid over an exponentially stretching sheet through a porous medium. J Power Tech 93(2):122-132

Sreenadh S, Pallavi AR, Satyanarayana Bh (2011) Flow of a Casson fluid through an inclined tube of non-uniform cross section with multiple stenoses. Adv Appl Sci Res 2(5):340-349

Wang CY (2012) Natural convection on a vertical stretching cylinder. Commun Nonlinear Sci Num Sim 17:1098-1103

$\mathrm{Xu} \mathrm{H}$, Fan T, Pop I (2013) Analysis of mixed convection flow of a nanofluid in a vertical channel with the Buongiorno mathematical model. Int Commun Heat Mass Tran 44:15-22 